with gradual dilatation of the cystic duct and migration of stones from the gall bladder. ${ }^{3}$

There are several clinical implications. The long contiguous course of the cystic duct and common hepatic duct could explain why surgeons sometimes inadvertently leave a long remnant of cystic duct, which is reputedly a cause of the postcholecystectomy syndrome. ${ }^{4}$ Furthermore, the migration of stones from the gall bladder into the contiguous segment may explain transient episodes of jaundice and, with more severe impaction of stones, cause persistent obstructive jaundice, the so called Mirizzi syndrome.
We thank Mrs H P Essel for her help. The study was supported by the South African Medical Research Council and the Staff Research Fund, University of Cape Town.

1 Maki T. Pathogenesis of calcium bilirubinate gallstones: role of $\mathrm{E}$ coli, beta-glucuronidase and coagulation by inorganic ions, polyelectrolytes and agitation. Ann Surg 1966;164:90-100.

2 Trotman BW, Soloway RD, Ostrow JD. Pigment vs cholesterol cholelithiasis clinical and epidemiological aspects. American fournal of Digestive Disease 1975;20:735-40.

3 Taylor TV, Armstrong CP. Migration of gall stones. BrMed f 1987;294:1320-2. 4 Lasson A. The post cholecystectomy syndrome: diagnostic and therapeutic strategy. Scand J Gastroenterol 1987;22:897-902.

5 Dietrich KF. Die hepatikusstenose bei gallenblasenhals und zystiklusstienen (Mirizzi syndrome). Bruns-Beiträge zur Klinischen Chirurgie 1963;206:9-22.

(Accepted 23 March 1988)

\section{Patients' knowledge of sublingual glyceryl trinitrate}

\section{George R Bailie, Elizabeth A Kay}

Department of Pharmacy, University of Manchester, Hope Hospital, Salford M6 8HD

George R Bailie, PHARM D, principal pharmacist

Elizabeth A Kay, MSc, staff pharmacist

Correspondence to: Dr Bailie. drug.

\section{Patients, methods, and results}

Glyceryl trinitrate has been used to treat angina pectoris for many years, yet no formal studies have established patients' understanding of its use. We showed that an information booklet can educate patients about sublingual glyceryl trinitrate,' and we report a study to determine patients' knowledge of this

We designed a questionnaire to assess inpatients' knowledge of their prescribed glyceryl trinitrate. Questions were included about how glyceryl trinitrate works, dosage, how to take and store it, side effects, and what to do should side effects occur. Fifty patients, 28 men (mean age 62 (SD 11.6) years) and 22 women (mean age $67 \cdot 4$ (12) years), were studied. The mean time of treatment with sublingual glyceryl trinitrate was $5 \cdot 5$ years (range one week to 12 years).

Only one of us (EAK) collected data from the questionnaire. Correct answers scored one point and incorrect or "don't know" responses none. Two questions required multiple answers. A maximum score of six points was awarded for knowing how to take a tablet correctly, one point being given for each of tipping some tablets into the bottle cap, selecting one; sitting down or standing still for a moment; placing one tablet under the tongue; not eating, drinking, or smoking while taking the drug; and replacing the cap of the bottle tightly. A maximum of four points was awarded for side effects, one for each of headache, flushing, dizziness, and burning sensation in the mouth. The correct answer for the drug's dosage was taking a maximum of three tablets in 15 minutes - the second tablet five minutes after the first and the third five minutes after the second-and thereafter seeking medical help if this regimen was ineffective.

Only 15 patients remembered receiving advice about their tablets. Forty seven patients knew the indication for their use. Most called their tablets GTN, and 13 also knew them as either TNT or trinitrin. Six patients understood glyceryl trinitrate's mode of action. Six patients understood the word "sublingual," and 25 knew that these tablets could be used prophylactically. The patients' knowledge of the dosing, storage, and side effects was poor (table).

\section{Comment}

Patients showed a depressing lack of knowledge of their drug treatment, and many did not know how to take sublingual glyceryl trinitrate tablets correctly.
Patients' knowledge of administration, dose, storage, and side effects of sublingual glyceryl trinitrate $(n=50)$

\begin{tabular}{lc}
\hline Knowledge tested & $\begin{array}{c}\text { No of patients } \\
\text { giving correct } \\
\text { responses }\end{array}$ \\
\hline Administration ${ }^{\star}$ and dose: & 22 \\
Time to onset of action & 2 \\
Duration of action & 31 \\
Action if first dose ineffective & 7 \\
When to take second dose & 6 \\
Maximum dose over 15 minutes & 38 \\
Action if three doses ineffective & 24 \\
Storage: & 9 \\
Store in glass container & 14 \\
Reason for storing in glass & 9 \\
Storage conditions required & 25 \\
Reason for storage conditions & \\
How often to renew supply of tablets & 26 \\
Side effects: & 21 \\
Whether tablets produce side effects & 2 \\
Knowing one or more side effects & 1 \\
How to avoid headache & \\
How to avoid dizziness & \\
\hline
\end{tabular}

ॠFifty patients knew a mean of $3 \cdot 0(\mathrm{SDI} \cdot 0)$ of six points about taking tablets correctly.

Only $62 \%$ knew what to do if the first tablet was ineffective; the remainder said that they would either call an ambulance or their doctor, neither of which is appropriate. Most patients $(88 \%)$ did not know the maximum dose and some thought that it was more than eight tablets. The maximum dose is not on the label and patients must be told it by their doctor or pharmacist. That patients are informed about the maximum dose, however, should not be assumed. ${ }^{2}$ The mean score for taking the tablets correctly was $3 \cdot 0$, which indicates a severe lack of knowledge. Labels on bottles containing glyceryl trinitrate tablets give an expiry date of eight weeks after the bottle is first opened, but only half of the patients knew this. Finally, the patients' anecdotal statements typified their poor understanding: one patient thought that the tablets caused an explosion in blood vessels, two said that sublingual meant having a speech impediment or the ability to speak two languages, and one said that he stored his tablets loosely wrapped in a handkerchief.

Clearly these deficiencies require correction. Written information is generally considered to be beneficial in increasing patients' knowledge of their medicines, ${ }^{3}$ especially when combined with oral information. As instructional materials are available for other formulations of glyceryl trinitrate so a suitable booklet ${ }^{1}$ should be made available to all patients who receive sublingual glyceryl trinitrate.

We thank Dr A Bernstein for allowing access to his patients.

1 Kay EA, Bailie GR. Educating patients about sublingual glyceryl trinitrate. Pharmaceutical foumal 1987;239:R3.

$2 \mathrm{McMahon} T$, Clark CM, Bailie GR. Who provides patients with drug information? BrMed F 1987;294:355-6.

3 Anonymous. Drug information for patients: keep it simple. [Editorial.] BrMed J 1980;280:1393.

(Accepted 22 March 1988) 